\author{
St ud i a P i los ophic a \\ Wrat is l a vi e n s i a \\ vol. XIV, fasc. 1 (2019) \\ DOI: $10.19195 / 1895-8001.14 .1 .1$
}

STEVEN E. PEÑA

ORCID: 0000-0002-1541-288X

San Jacinto College, Texas, USA

\title{
Alasdair Agonistes: MacIntyre and a New Discontent with Modernity
}

\begin{abstract}
This paper is an examination of certain assumptions that, I hold, lie in the background of MacIntyre's conception of the formation of the intellectual schema as found, most prominently, in Whose Justice? Which Rationality? and Three Rival Versions of Moral Enquiry. A thorough examination of MacIntyre's concept of the rational schema, I will show, reveals that the parsing he proposes to carry out on intellectual history is confronted with a problem that finds its analogue in the field of biological taxonomy. In order to carry out this project of determining where the seams lie in intellectual history one must first recognize that the parsing itself is a scheme-dependent undertaking. As such it is not unlike the necessarily somewhat arbitrary identification of species and genera in the biological realm. In other words, it should be recognized that intellectual history, like the morphology of the plant and animal kingdoms, is continuous, not discreet. An almost wholly unexamined assumption that stalks through Whose Justice? and Three Rival Versions is that there are something like intellectual natural kinds in the history of ideas. Indeed, the notion that there are "traditions" at all (in the sense in which MacIntyre uses the term) may be a highly conventional artefact of an Enlightenment-era view of intellectual progress. This leads me to conclude that MacIntyre has failed to observe that the view of traditions and schemes neatly succeeding one another, on which much of his critique is dependent, is itself a product of the perspective he calls "encyclopedia." This, in turn, will make manifest why it is that almost all of MacIntyre's examples of rational scheme-switching are from the natural sciences rather than the normative, a fact I will show is connected to a paradigm of linear progression that one tends to find in the exact sciences, but not in praxis.
\end{abstract}

Keywords: relativism, intellectual schema, traditions 
"And all the workers of Iniquity rose up" I Maccabees

Let us imagine for a moment the parade I espy marching down the broad avenue of modern intellectual life; it is a parade more clearly leaving someplace than going to one. For this is the parade that has been moving for some decades now; it is the parade marching away from modernity. Of course, no single individual leads this motley assemblage, but some quite recognizable faces may be discerned among those in the forefront. Some, not a few, in fact, hail from the Left Bank and others have been seen disporting themselves near the murky waters of the Rhine. A great deal of confidence these leaders have, a confidence reminiscent of the sanscoulottes leading off Robespierre and his ilk, leading off, that is, the very ones who have led them to where they are now. And yet no 18th Brumaire is this; for among those lusty leaders, we find none marching with more gusto than one familiar not with the Seine nor the Rhine but with the twin, less turbulent waters of the Tweed and now the Tiber, viz. Alasdair MacIntyre.

If we listen closely we shall hear some among this jolly lot singing the "Internationale," but these have of late fallen to the back. Most of the rest produce a strange cacophony which we are told really has its own peculiar sort of harmony produced by diversity; that is, they are singing in all the different keys at once. And if we protest that this harmony sounds in fact rather disharmonious to us we are given a response, not unlike that given by Cassius to Brutus - the fault is in our ears.

Now what is most telling about this parade is that while most of its eclectic gang of drum majors is turning down the road it proudly styles "postmodernity," Alasdair MacIntyre and his comrades, we are told, have taken the road to pre-modernity. But is that truly what MacIntyre has done? More on that anon.

MacIntyre has had more than one intellectual reincarnation. It was not all that long ago, in fact, that his own mellow baritone was heard to blend in with those melodious strains of the "Internationale." This has been a long-time flirtation of his and he certainly remains today highly distrustful of liberal market economics and its supporting institutions, social attitudes and, perhaps, even the concomitant conception of selfhood it allegedly promotes. This places him broadly in the tradition of G.K. Chesterton, who is himself, I think, in the line of Thomas Carlyle; that is, they are essentially what we should today call "Christian socialists." All along, however, MacIntyre was to some significant extent given to the methods, prejudices and metaphors of philosophy as done in the Anglo-American tradition. And yet today we find that whatever remains of MacIntyre's Celtic sense of the logical, his preference for analytic philosophy has gone the way of his brogue and is now little more in evidence than the latter. More important, however, than the new avenues he has taken in methodology is the trail MacIntyre has blazed in the broad realm of reason and conceptual schema. Here, particularly as enunciated in Three Rival Versions of Moral Enquiry, he is seen to be advocating an understanding of those categories which is postmodernist. MacIntyre has, after all, indicated 
that the Thomism he now loves so dearly is, simply, the best way of conceiving the truth, of reality and of the world in general that we currently have. What this means, as MacIntyre is quick to explain, is that another, more powerful, more useful conceptual scheme may arise and give us reason to abandon Thomism.

So how is it that Thomism is in some sense superior to its rivals? Why is it currently regnant? Well, it is the case, MacIntyre insists, that Thomism's rivals are presented with crises of their own making (or, to use MacIntyre's own language, they run into dead ends or are self-contradictory on their own terms), which can be better understood and genuinely resolved on Thomistic grounds, while the converse is not the case.

Now it seems clear that MacIntyre's account of the superiority of the Thomistic scheme will not be a heavy enough superiority for many Thomists. Why, they will ask, should they give up their realist birthright for such postmodern pottage? For it seems we may summarize MacIntyre's view as that a conceptual scheme may indeed be shown to be rationally superior but not objectively "correct"; for the latter claim entails the further claim that "no fundamental reality could ever be disclosed about which it is impossible to speak truly within that scheme."1 This is a recognition that any conceptual scheme, including a Thomistic one, may eventually find itself in an epistemological crisis.

Now the first order of business is to do justice to MacIntyre's argument by first determining the nature of his thesis. Consider, for example, first of all, what it means to offer various assertions in the realm of moral philosophy. Descriptivism and subjectivism, however they might be connected to larger ontological issues, are best understood as linguistic or conceptual theses, for example. They do not, in other words, strictly speaking, assert the existence, or in the case of subjectivism, the lack thereof, of moral facts. These theories do not purport to tell us what exists in the world; in short, they are not ontological theses. This has to be contrasted with moral realism and scepticism. The latter types assert something about the "furniture" of the world (as philosophers are wont to speak). The philosopher who forwards a sceptical thesis, for example, is telling us what kinds of things we will not find among that furniture. Now I think it is best we see MacIntyre as positing a conceptual or rational thesis vis-à-vis an ontological one. I think we will have the clearest insight into his argument, in other words, if we understand him to be saying something about rational constraints and limitations rather than the furniture of the world. For this reason, further, I think that charging MacIntyre with anti-realism, and by implication, accusing him of not being a true Thomist, in a sense misses the point; i.e., it is just to fail to understand the nature of his primary thesis in Three Rival Versions; that is, it is to fail to recognize it as a conceptual thesis. Now the system of St. Thomas allows us to extrapolate a set of assumptions and working hypotheses and principles, formulated in the context of a set of medieval debates and issues, and apply them to prototypically contemporary problems. Among those beliefs that form a part of the Thomistic system,

${ }^{1}$ A. MacIntyre, Three Rival Versions of Moral Enquiry: Encyclopaedia, Genealogy and Tradition, Notre Dame 1990, p. 121. 
however, are various ontological ones, such as the existence of God and of the soul. Now, if MacIntyre were telling us something that had direct implications for these issues he might be vulnerable to the charge of scepticism and, perhaps, anti-realism. But he is not. At the very least this reading, then, will serve to purchase charity, a valuable philosophical commodity, if, at times, at the price of a slight loss of perspicuity.

That being clarified, it must now be noted that, if MacIntyre is not fairly styled an anti-realist, he certainly is vulnerable to the charge of relativism. What is important, though, is just what he is a relativist about. If I am correct in my assessment of the nature of his thesis MacIntyre is a relativist about the rational schema. He will hold that what is deemed rational must always find its justification within a particular conceptual scheme, and between conceptual schemes, there is always a failure of translation. What I cannot do is hold up the conclusions I find rational and measure them up with some body of truth independent of any conceptual scheme. This mistaken view is just the stance taken by the encyclopedist and attacked by the genealogist. For the body of truth against which I measure a given conclusion is itself scheme-constructed; it is the product of more fundamental sets of conclusions, themselves justified by criteria internal to the scheme.

We should be careful to notice here, however, that the preceding claim of MacIntyre's, however consequent with it, is not the claim that there is no objective truth. Indeed, I find no place in Three Rival Versions where its author makes just that very claim. MacIntyre's very complicated theory is consistent with the notion of transcendent truth beyond all schemes. What is not scheme-transcendent is the justification of a given "truth" along with the notion of an arriving-at the true. The idea of hitting upon a 'truth' independent of a history of inquiry MacIntyre finds particularly unpalatable and the unfortunate detritus of an Enlightenment prejudice. Within this essentially coherentist model of rational justification, then, we can neither identify nor justify truth independent of rationality, hence the incommensurability not just of schemes but of truths. Thus our appeals for others not sharing our conception of the rational to accept those truths are bound to fail. Still, the truth remains as that outside all schemes but perceived or grasped only within a scheme.

It may be difficult to articulate this except via metaphor; thus, metaphorically, perhaps we may characterize the situation as one in which while it is the case that I can only view truth through the lenses of my conceptual scheme (indeed, I can identify it only while sporting a given set of lenses), there nevertheless is truth outside of my own and all other schemes. Here is how we may view the status, then, of truth and rationality among the three rivals genealogy, encyclopedia and tradition (a circle represents a conceptual scheme; see Figure 1).

Now MacIntyre should have no objection to conceiving of the totality of the propositions of a given scheme as a set of boundary conditions that define and carve out a sort of conceptual space, the contours of which delimit the conceptually possible within the scheme in question. Thus, at any time for any given conceptual space occupied by a conceptual scheme, there is a finite set of propositions, be their truth-values what they may, that are consistent with the parameters of 

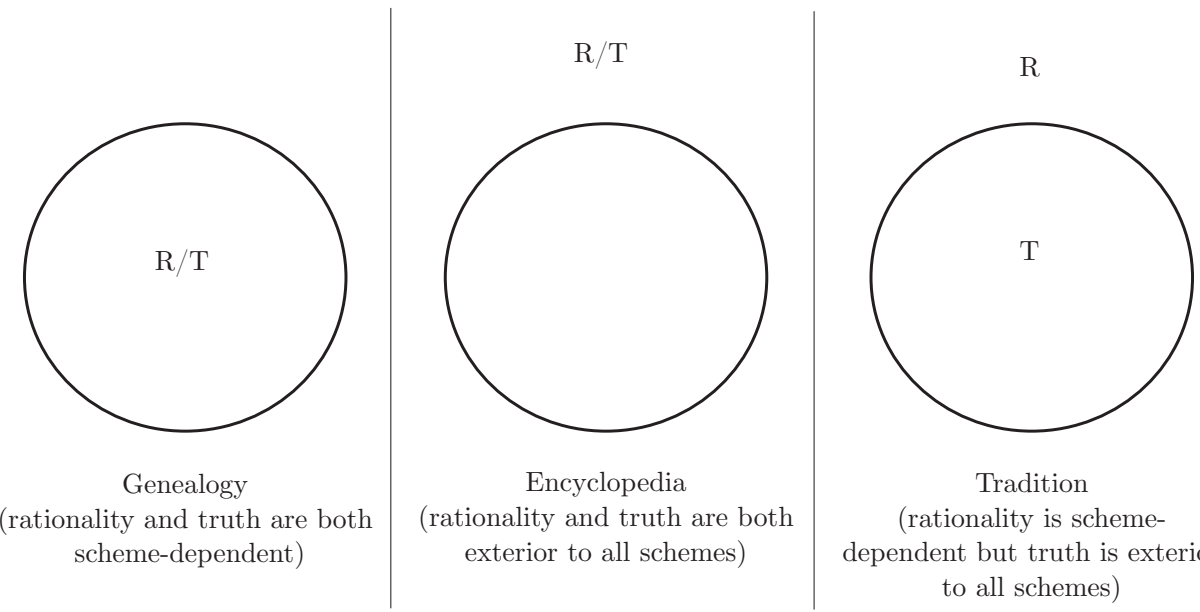

dependent but truth is exterior to all schemes)

Figure 1. MacIntyre's conception of three competing schemes.

Source: own work.

that space. Now, though it is not something MacIntyre considers, and never mind whether it is anywhere the case, it is entirely conceivable and therefore logically possible that two distinct communities with non-identical languages could occupy an identical conceptual space. Thus all the propositions affirmed by community $A$ are just those held by community $B$, but the natural language of the members of community $A$ is Russian and that of community $B$ is, say, Swahili. I understand MacIntyre's views to commit him in such a case to holding that the languages of the two communities must be translatable. How this plays out we shall see below.

First, however, it will be observed, on even a mere cursory reading of Three Rival Versions, that MacIntyre has little (almost nothing) to say about the status of truth per se. He seems to suggest that he sees truth as an objective fact, that is, as a part of the furniture of the world. Yet it must be admitted that he seems singularly unconcerned with securing the status of truth. Such is the case, I will suggest, for the very reason that his thesis does not concern that status; it does not, that is to say, turn on the status of truth.

Yet, one nagging question here that must surely give us pause is whether MacIntyre, on this perspectival account of rationality, is truly doing justice to the incommensurability thesis. For to accept it is to hold to a belief that it is as if we all had on certain lenses, as it were. I sport the lenses of my conceptual scheme; call them my A-lenses. Now, despite MacIntyre's description of the situation, it does not seem to me that I can simply imaginatively look at scheme B. This is because my "looking" is not done with a naked eye - for there is no naked-eye-looking; rather, I am looking over at B through A-lenses. It may even seem that B looks rather inviting, that $\mathrm{B}$ provides resolution to my A-problems (this whole story of intellectual voyeurism is told in Chapter 5 of Three Rival Versions). Nevertheless, I am still viewing B through A-lenses. In order to truly understand B or fully comprehend B-statements, nay even do justice to them, must not I wear B-lenses? 
Like Dennett says of evolutionary theory that the incommensurability thesis is a sort of universal acid that corrupts whatever is designed to contain it. On the incommensurability thesis even to accept MacIntyre's description of what genealogy and encyclopedia are seems to suggest that we may be sure he is observing those schemes from some scheme-independent perspective, some conceptual outer-space. On his principles, however, that cannot be the case. Indeed, we can only, again on his principles, read MacIntyre's book from within one scheme.

Allow me to back up just a moment and suggest an analogy here. Is not much of this comparable to the situation with biological taxonomy? To do justice to the conceptual scheme thesis we will have to admit that the parsing of "traditions," i.e., determining where the seams lie in our intellectual narrative, is itself a scheme-dependent undertaking. It is not unlike the necessarily arbitrary identification of species and genera in the biological realm. That is, must not we recognize that intellectual history, like the morphology of the plant and animal kingdoms, is continuous, not discreet? An almost wholly unexamined assumption that stalks through Whose Justice? Which Rationality?2 And Three Rival Versions is that there are something like intellectual natural kinds in the history of ideas. The attention and critical analysis that MacIntyre has so eloquently drawn to the questionable notion of identifying truth independent of a history of inquiry have served him well in his efforts to deconstruct traditional notions of rationality and objectivity. But it appears to be an insight, however valuable it may be, that eats its own young. MacIntyre has failed to observe that the view of traditions and schemes neatly succeeding one another, on which much of his critique is dependent, is itself the product of the perspective he calls "encyclopedia."

Well, let us assume for the moment that there are the sorts of discreet intellectual entities MacIntyre traffics in; the larger point is that his taxonomy is scheme-dependent. Where he has no problem perceiving a clear distinction between, say, David Hume and modern liberalism, a stoic maharajah from the subcontinent may not and likewise Hume and MacIntyre may gloss over what the maharajah sees as clear breaks in Eastern philosophy. Indeed, perhaps we need to consider whether the notion that there are even traditions at all may be a highly conventional artefact of an Enlightenment-era view of intellectual progress, and concomitantly, of the rise of an independent discipline of philosophy in the universities of the Anglo-Saxon world. Let us notice the sort of enterprise MacIntyre is engaged in. Biologists draw a distinction between alpha and beta taxonomy; the former involves identifying new species, i.e., it recognizes the existence of previously unidentified species; the latter concerns itself with the ordering or reordering of preexisting, or, more accurately, prerecognized, species. Thus, beta taxonomy concerns itself with how the atomic units of taxonomy (species) should be arranged or placed into various higher taxa, some of the latter of which may be newly formed for this purpose. MacIntyre is doing beta taxonomy in the history of ideas. $\mathrm{He}$ is placing people and ideas into conceptual taxa, and doing so in a way, to be sure, that is illuminating and insightful. But his conceptual beta taxonomy leaves

\footnotetext{
${ }^{2}$ A. MacIntyre, Whose Justice? Which Rationality?, Notre Dame 1988.
} 
several questions unanswered or simply glossed over. How, for example, are we to understand the matter of a conceptual scheme failing on its own terms? That is, how are we to distinguish the phrase "failing on its own terms" from simply "self-contradictory"? That a scheme, idea or thesis is self-contradictory is already a charge commonly met within the academy. But if the charge of self-contradiction is so common we are presented with the further question of whether what MacIntyre has done is simply to restate a traditional problem, if, to be sure, with a great deal more lucidity and eloquence. When we go a step further and admit that there can be such a thing as a pair of schemes wholly, or almost wholly, incommensurable we are told that, nevertheless, they can yet have "significant" untranslatability and incommensurability and yet be objectively compared. ${ }^{3}$ We are left wondering how "significant incommensurability" is to be unpacked. More importantly, an intellectual beta taxonomy presupposes the existence and coherence of the previously identified conceptual species. It implicitly accepts the legitimacy of the alpha taxonomy upon which rests, and by means of which is defended, the coherence of its own critique. It is as such that I am suggesting that this insightful analysis of the history of ideas given us by MacIntyre, rich and helpful as it is, nevertheless remains, though apparently unnoticed, above all a project deeply infused with and animated by a spirit of encyclopedia. In other words, in essence, his project is one of encyclopedic beta taxonomy. This conclusion I will leave aside for the moment.

Certainly, the very existence of conceptual schema has been brought into question by, among others, Donald Davidson, someone McIntyre gives inadequate attention to. Now, what I think I see going on here is something I do not think I quite know how to express, but for which I think I may give plenty of examples. Here is one: it seems to me that we tend to think there is nothing problematic with many even rather pedestrian observations of academics of the type such as that " $x$ was how the Elizabethans viewed science" while we would think it unreasonable to say something similar, that is to capture our diversity of belief in so simple a formula, of our own age, even of a society not nearly so heterogeneous as our own, as in " $x$ is the view of the death-penalty in Japan today," or " $y$ is the twenty-first century view of sex." Now, I do not want to overstate the case here; there are certainly reasons why it is at least marginally more reasonable to ask what the Elizabethan view of science was than to ask a similar question about our own society. What I want to hold is that MacIntyre overstates, or rather, assumes, the opposite case (this is not a question he considers). Much of his critique in Whose Justice? and Three Rival Versions rest upon a view of intellectual history in which ideas are much more calcified, periods are much more stratified and beliefs considerably more monolithic, than, I will suggest, they actually have been. The charming story MacIntyre tells about traditions and schemes neatly succeeding one another is insufficiently reflective of the actual events to support his thesis; the real events, to continue the metaphor, seems more like a James Joyce novel, sans chapters, with plots and counterplots working at cross-purposes. Here is how MacIntyre defines a "living tradition": "a historically extended, socially embodied argument, and

\footnotetext{
${ }^{3}$ A. MacIntyre, Three Rival Versions, p. 5 and see also ch. 5.
} 
an argument precisely in part about the goods which constitute that tradition."4 Ironically this broadly historical analysis with a predilection for exposure and debunking is an arrow out of the genealogical quiver: it was Michel Foucault, taking his cue from Friedrich Nietzsche, that presented us with an early analysis of the "myth of the lofty origin," and in doing so, one may suspect, was himself guilty of the genetic fallacy.

This assumption about a more calcified set of ideas in intellectual history is intimately connected, I want to hold, to what perhaps seems at first merely an oversight of MacIntyre's in Three Rival Versions, but which, on closer inspection, we may see as a necessary concomitant of that assumption. I am speaking of the dearth of examples in rational scheme-switching from the normative sciences rather than the natural. This is important, I think, if for no other reason than the fact that it is praxis that in the end, MacIntyre is most interested in. MacIntyre's paradigm example, of course, is that of the Copernican system superseding the Ptolemaic. Adherents of the older system could "imaginatively look outside" their scheme to see that the newer had solved the problems of the older system. He offers something similar with regard to impetus theory, referencing the conceptual frameworks of Aristotle and Galileo. So why is it we are not given any more than the merest hints of all this in ethics? Perhaps the constraining aspects of physical laws create a manner of movement in the natural sciences that gives the appearance both of linear progression and of the possibility of the rational superiority of one scheme over another (through the phenomena of epistemological crisis and sterility), and both of these, I am suggesting, are misappropriated when applied to the normative sciences.

The matter of progression in ethics is belied by the manner in which rational agents switch conceptual schemes. In scientific matters there is clearly, by and large, a historical progression seriatim; in normative matters, by and large, there is not - that is why my Aristotelian moral views will be welcomed in the modern academy but my Aristotelian biology will not. Scientific theories, once broadly disseminated, tend to sweep away all before them; that is not typically the case in moral matters. And significantly, MacIntyre, in Three Rival Versions, would conflate the two realms of inquiry, not stopping to notice that the vast differences between them underlie his own inability to offer us anything but scientific examples in a book that is preeminently axiological in its central theses. That one might be entirely competent in the humane and social sciences and yet embarrassingly uninformed in the exact sciences was something MacIntyre should have been well aware of in his early days as a sociologist, as it was a point being made with all the vigour of a religious enthusiast by his compatriot across the Tweed; I mean, of course, by C.P. Snow. But it is a fact all too often lost on us that only science can cast out science. Consider, for example, this whole matter of imaginatively looking outside one's own scheme in order to view another. This sounds an awful lot like a sort of epiphany, something one rarely finds in normative matters but which is paradigmatic of theories in the natural sciences. What is far more likely to happen

${ }^{4}$ A. MacIntyre, After Virtue: A Study in Moral Theory, 2nd ed., Notre Dame 1984, p. 222. 
in the realm of value may be seen in the experience of MacIntyre himself. The prolific Scotsman began a gradual turn in his outlook around 1980, after a lengthy interim period in which he had begun to reject his earlier views embodied in such works as A Short History of Ethics and Against the Self-Images of the Age. This resulted in the seminal work After Virtue, in which he argued that classical prescriptive deontology is simply irrational in the absence of a transcendent legislative authority, divine or otherwise. This moral odyssey is not atypical in terms of its gradual movement among rival theories. When a given scientific theory succeeds another, however, it is most often embraced of a sudden, in the manner described by MacIntyre; what may be slow is its dissemination.

This brings us to a consideration of incommensurability and untranslatability. I will assume here that Donald Davidson has clearly shown that the incommensurable reduces to the untranslatable; so we may deal with the issue in terms of the latter. It is worth wondering how many of encyclopedia's postmodern critics in the latter's natural home in the English speaking world, i.e., in English and anthropology departments, realize that the untranslatability thesis was first concisely put by Willard Van Orman Quine. Yet Quine may be taken seriously even while we view his critique as simply showing us something rather curious about the prospect of precisely translating one language into any other. Of course, MacIntyre prefers to speak of conceptual schemes. What I want to notice here is that because, as I have tried to show, traditions and schemes are not sufficiently demarcatable, because intellectual history is continuous, not discreet, analog not digital, if you will, a conceptual language is like a verbal natural language; it is amorphous in its boundaries; it immediately reduces to a congeries of patois, even pidgins, if you like; it is, above all, organic. The important question for us here, as I see it, is whether a crucial aspect of MacIntyre's thesis rests on the assumption that language, like biological species, is a relatively stable phenomenon. I suppose this is similar to Bertrand Russell's critique of the notion of substance, but the critiques are not logically connected. It might be interesting to ask MacIntyre if he thinks that a faculty member of the University of Paris in, say, the year 1260 could hold to an entirely different conceptual scheme than his fellows "down the hallway," so to speak. If a given conceptual scheme, as MacIntyre has told us, is at least in part a product of the social, cultural and political institutions of the society in which it arises, just how could there be serious dissenters in the middle of all that? This is a part of his otherwise very interesting story that MacIntyre has unfortunately left out. Consider, however, that several scholars, most notably, I think, Sir Isaiah Berlin, have shown that there were Enlightenment thinkers, chief among them perhaps Johann Georg Hamann, who, though in the middle of it all intellectually, dissented from the entire program. MacIntyre feels confident, confident enough, that is, to spend very little time defending the thesis, that in the middle of the 13th century Augustinianism was a distinct conceptual scheme from Christian Aristotelianism. Would modern well-informed intellectuals, in general, see it and parse it that way today? They might see it all as the Christian intellectual tradition and its internecine disputes. Would we say a Freudian and a Skinnerian have different schemes? Probably the Freudian and Skinnerian would insist they do. 
How about a Freudian and a modern neurobiologist? Clearly, they have distinct concepts. Neither the modern neurobiologist nor the modern psychologist will use the pleasure principle in his treatment of his patients and hardly will they agree to the sexual aetiology and pathogenesis of all the possible psychoneuroses. Yet the use of radically diverse concepts does not constitute a diverse conceptual schema.

We are never given much of a defence in Three Rival Versions of this notion of a conceptual scheme that these works traffic in so much. It would have been nice, if MacIntyre had told us whether, with this sort of dualism between theory and content, i.e., between a conceptual scheme and the facts organized by it, what is being organized is the world or my experience of the world. Is the conceptual scheme I labour under, in other words, putting together some objects out there or my phenomenology of those object, my $P$ objects, if you will? For if what our conceptual scheme organizes is $P$ objects rather than objects, we will register Plato's complaint about mimesis in book $\mathrm{X}$ of the Republic; that is, we are now at two removes from the truth, and MacIntyre has given us no apparatus for dealing with this. One may, of course, hold that it is events, not objects, that we are organizing, but I cannot see that this changes anything relevant.

Nor has MacIntyre told us why it is we should locate a conceptual scheme at the level of a culture or society or tradition instead of at that of the individual. Why should we not say that I have a conceptual scheme all my own? After all, I need not have a different language in order to have a set of entirely different meanings. Think of how the early moderns used terms such as "gravity," "mass," "energy" and the ever-irritating "idea." It is conceivable, in fact, that one's vocabulary might match up one for one with that of other speakers and yet every meaning between identical terms be distinct. Surely when MacIntyre hears words like "taxes" or "holocaust" he conjures up ideas and associations, relations if you like, that are quite distinct from those these words conjure up for others. So must not we admit that we can even speak the same language and in a sense not really do so? We will agree, I think, that we cannot organize a single atomic object or event; it follows, then, that if we all have a conceptual scheme we must all see a plurality of objects or events when we look at the world. There is at least that minimum of agreement. But cannot we go further? Whether it is an 8th-century monk contemplating the music of the spheres or a modern astronomer at his radio-telescope, should not we conclude that if their respective conceptual schemes did not at least largely fit the world, which MacIntyre tells us is really out there, they could not function within the world that is really there? And is not this in turn tantamount to admitting that all schemes (if there really are multiple ones) are at least largely true, or if we are more timid, largely correspond to the world? This is another reason for concluding that the real issue comes to the matter of translation. In fact, MacIntyre's failure to identify necessary and sufficient conditions for the existence of a conceptual scheme, or failing that, something at least approximating such, in order to give us something like a Wittgensteinian family-kind term, is, in my opinion, a glaring lacuna in his theory.

In fact, in recognizing this lacuna we may be given pause about another part of the story. I mean the way in which MacIntyre tells us people may come to embrace 
what is for them a new conceptual scheme. What is supposed to happen is that a person finds that his/her original scheme or narrative is faced with an epistemological crisis. This, in turn, leads this person to consider an alternative paradigm. Now to consider this story at length would take us too far afield; I simply, therefore, would like to suggest that, theory aside, often enough it just has not been that way in the real world. Consider just one case by thinking about the makeup of humanities and social sciences departments before 1991. Something perhaps like half the faculty some stripe of Marxist. Today at the average university (in the English speaking world anyway) their numbers, I mean that of the Marxists, are not likely to make up a good basketball team, or for MacIntyre's sake, a good cricket team. It was not any epistemological crisis that brought this about; it was political collapse, and there was not some new conceptual scheme those Marxists all jumped to.

But to get to the heart of this matter of identifying conceptual schema, we may take note that MacIntyre has given us at least one necessary condition: there must be a failure of translation between supposed rival theories. Yet translation seems to have served MacIntyre himself quite well-we notice that he has always had a great deal to say about ancient Greek moral concepts; presumably, he finds the language of arête and hubris amenable to translation into modern Scots' English. It should be remembered, however, that there is a long history of the use of all types of languages, natural and otherwise, and supposed untranslatability, to exclude. This is a not uncommon phenomenon in the philosophical community also. Analytic philosophers have long insisted that much of what is philosophically important cannot be expressed except in the language of symbolic logic. Many neo-Thomists too have long done the same thing with the use of Latin in a transparent attempt to make of themselves an initiated priesthood of medieval interpreters; fortunately, MacIntyre is free of this particular type of silliness. Free also is he of the reductionist tendency of those he in another place refers to as the "philological Aristotelians," the ones who seem to think that doing philosophy amounts to telling us how certain Greek and Latin words have been used over time.

There is, of course, an old view that any given natural language contains within itself a unique way of viewing the world and of organizing experience. Perhaps this is really what MacIntyre has in mind, as what is true in this regard of natural languages will be true a fortiori, of conceptual languages. After all, a way of viewing the world and of organizing experience is surely part of (if not entirely) what MacIntyre means by "conceptual scheme." Ironically, unless I am greatly mistaken, this view of natural languages is largely an Enlightenment-era theory. I know it was later argued by von Humboldt (Wilhelm, not Alexander) and after him by Max Müller and later it was a central component of Oswald Spengler's famous Decline of the West. But if this is what MacIntyre has in mind, he is then presented with the problem of why there are not as many conceptual schemes as there are natural languages or even groups of natural languages.

Now more directly in relation to that, i.e., to translation, pace Davidson, we can focus on human natural languages. Here the untranslatability thesis has a lengthy 
pedigree, including untranslatability by fiat or by religious dogma, as with the orthodox Islamic contention that the Koran cannot exist in any language except Arabic. Now acknowledging Quine's critique, which amounts to realizing that we can never know with complete certainty that a given proposition " $x$ " accurately translates a given proposition " $y$ " in another language (which is something like the problem of other minds, that is something we may not consider a real problem but nevertheless something we cannot definitively refute), we can admit, and surely must, that for all intents and purposes what can be said in Russian can be said in Swahili. That is to say that for any given declarative sentence in Russian there is some syntactically coherent string of phonemes in Swahili that denotes just that. Naturally there are concepts in the Russian mind that may be expressed with a single Russian word or phrase that will not be found in the mind of any Swahili-speaker and which hence cannot be conveyed with a single word or phrase in Swahili, but of course that is not the same thing as to say that it cannot be said in Swahili. One simple example: a cursory reading of the Latin Augustans, particularly works dealing with everyday life rather than belles-lettres, reveals that the Romans at that time had two distinct concepts corresponding to our English word "uncle." There was one's father's brother, patruus, and one's mother's brother, avunculus. So what are we to do since English does not distinguish between the two? Firstly, we must realize that it is not quite correct that English does not distinguish between them, but rather that our culture does not, at least not to the extent to give us separate words. Roman culture did make such a distinction; hence, they developed a corresponding vocabulary. It is not the case that the concept cannot be expressed in English; for I just did express it in when I spoke of my father's brother. It is not that we do not have the concept; we simply do not have a single word for it. In fact, some psycholinguists would assure us that if we cannot say it, at least mentally, we cannot think it, and I can think of my father's brother opposed to my mother's. The situation, thus, is not dissimilar to MacIntyre's own repeated use of the word "culture." This sense of the term, i.e., as the "totality of socially transmitted behaviour patterns," has been around for only a hundred years or so, and was given to us by the father of modern anthropology, Franz Boas, a consummate encyclopedist. Yet MacIntyre's use of it is not in the least anachronistic, as there were cultures and thoughts about cultures, in the sense of the term which MacIntyre uses, long before we had an English word for it. It should have been as evident to MacIntyre as it was to Aristotle that our mental vocabulary does not match up one for one with our verbal vocabulary; this would have spared him a lot of worry about the word "taboo." It was the consideration of such facts, I think, that led Roman Jakobson to declare that all cognitive experience is conveyable in any language. It seems to follow, then, that taking modern linguistic theory into account, to hold that the Russian speaker can say things the Swahili speaker cannot, amounts to holding that the latter cannot think them, a proposition which I hope is almost self-evidently false. I will go just a bit further in saying that, not only is it clearly difficult for MacIntyre to avoid conceding the possibility of translation but that I have the feeling that translatability is in fact presupposed here; it is something not unlike what Aristotle says of our 
presupposing the law of noncontradiction in our discourse; that is, my suspicion is that there is a massive petitio principii here concerning the possibility of translation lying at the base of Three Rival Versions of Moral Inquiry.

Now to step back and take a larger view, we may say, in the language of Quine himself, that perhaps this whole project is conceived in sin. For cannot we be forgiven for asking if it is not in fact but a species of a very old and familiar debate; I mean that over objective comparability in general. This is particularly important if (1) my critique of the assumption that intellectual history is essentially discreet, or as I said it earlier, that there are natural kinds in the history of ideas, and (2) Donaldson's reduction of incommensurability to untranslatability, hold water. For then we are back to asking if there is any real or true sense in which Shakespeare is better than Spike Lee. What I mean to say is that MacIntyre is very good at making ideas sound new which in fact are very old, and, further, he is very good at asking, and showing, where these ideas lead. The simple fact is, I think, that the vast majority in the academy today $d o$ in fact believe that Shakespeare is better than Spike Lee and Quentin Tarantino, which is just to say that the vast majority of the academy, consciously or not, subscribes to at least one important pillar of modernism, and, a fortiori, to encyclopedia.

Let it be recognized, then, that the terms "modernism" and "enlightenment" tend to be used in more than one way. As used to convey the notions that we live in a law-like universe, that knowledge is largely unified and that indefinite human progress is in principle possible, modernism is not only alive and well, it is, barring the type of event that has occurred only once in human history, I mean the fall of the Western Roman Empire, a process that is for all intents and purposes as irreversible as the first law of thermodynamics. But enlightenment as an ideology is indeed dead, not because it is unsupported, but for the simple fact that we no longer live in an ideological age. Most of our well-known scientists and philosophers of science simply take this for granted. It is and was taken for granted by the likes of Stephen Jay Gould, Daniel Dennett and arguably our foremost biologist, Harvard's Edward Osborne Wilson, who has penned a book about the unity of all knowledge,$^{5}$ another important pillar of the Enlightenment. These are and were all quintessentially enlightenment thinkers, and their influence in the academy is enormous.

Finally, I would like to notice MacIntyre's radical prescription for reforming the academy. Simply put, our jovial Scottish Thomist would like to see certain voices excluded, excluded for the sake of the debate itself. As radical as it seems, MacIntyre thinks this sort of academic culling would allow the real sort of debate, productive debate that is, to flourish. The modern university, then, should not be a marketplace of ideas where every thinker, however unusual or grotesque his ideas, can hawk his wares. No, the academy should be a place, he tells us, where debate can find rational conclusion, that is, where disputes can be finally settled and where definitive answers can be given. Ironically, this rejection of pluralism for pluralism's sake is prototypically modernist, which is why I questioned earlier what road MacIntyre has truly

${ }^{5}$ E.O. Wilson, Consilience: The Unity of Knowledge, New York 1998. 
taken. And it is just where we find, he tells us, the real difference between the Enlightenment and modern university, that is, in the former's conclusion of rational debates. The modern fragmentation of knowledge is so complete, MacIntyre explains, in part due to the fact that we have left the door open to all voices. Fragmentation produces cacophony, the cacophony of the parade of voices I began this piece by describing. I think this topic demands a proper discussion of its own; so I will not embark on such a discussion here. I will simply say that it seems remarkable that what MacIntyre fails to give even the most cursory consideration to is the possibility that perhaps the fragmentation of knowledge he so laments is simply an artefact of modern academic life rather than a mirror of reality. That is, he fails to consider that the phenomenon may supervene on the structure of modern university departments, where there is particularly, for example, the need to publish, which in turn demands originality, originality in regard to however circumscribed an intellectual bailiwick one finds it necessary to carve out for oneself. This is all furthered by the development of modern quantificational tools, and the possibility of an increase in quantification, I think, makes possible the increase of specialization. And why not? Plato himself, after a long calculation, tells us that the good king likes 729 times more pleasant life than the tyrant. Modern academic trends, then, almost demand that we all know more and more about less and less.

Well, Alasdair MacIntyre has had deep ties to the genealogical side of this, at least since the late 1950s, that is, since his Marxist era and his days teaching in sociology departments and publishing work on psychoanalysis. I suppose Thomists can be forgiven for being uneasy about his change of heart and his unusual brand of Thomism. After all, it is possible that he will eventually tell us that even truth itself is internal to a scheme.

Yet whatever direction he takes, I want to say for the record that, despite my feeble criticisms outlined here, I think what he has offered us in Three Rival Versions is simply brilliant, however mistaken I personally believe some of his theses are. Surely any number of us on reading this thrilling work mentally shouted an Archimedean "Eureka!". So I will offer the only payment an indigent Socrates could offer Thrasymachus - my praise.

\section{Bibliography}

MacIntyre A., After Virtue: A Study in Moral Theory, 2nd ed., Notre Dame 1984. MacIntyre A., Three Rival Versions of Moral Enquiry: Encyclopaedia, Genealogy and Tradition, Notre Dame 1990.

MacIntyre A., Whose Justice? Which Rationality?, Notre Dame 1988.

Wilson E.O., Consilience: The Unity of Knowledge, New York 1998. 